\title{
DOES BRAND IMAGE RESULT IN PLACEBO EFFECT? \\ AN EXPERIMENTAL STUDY ON SOFT DRINKS
}

\author{
Assoc.Prof.Dr.Ayla ÖZHAN DEDEOĞLU, Ege University, Faculty of Economics \\ and Administrative Sciences, Department of Business Administration, \\ ayla.dedeoglu@ege.edu.tr \\ Yeliz AYANGIIL, yeliz.ayangil@soobee.com.tr
}

\begin{abstract}
In medical researches placebos are used in order to distinguish between patients' responses to pharmacologically inert and active substances in treatment. Placebos have impact on treatment by promote positive psychological effects. The phenomenon can also be applied into the consumption context, where consumers' salient beliefs and expectations can activate subjective/behavioral outcomes. In order to find out if brand image give rise to a placebo effect, we conducted an experiment with famous soft drink brands. The findings demonstrate a weak placebo effect, which occurs at the conscious level of consumers.
\end{abstract}

Key Words: Brand image, placebo effects

\section{INTRODUCTION}

Brand is traditionally defined by the American Marketing Association (2008) as "a name, term, design, symbol, or any other feature that identifies one seller's good or service as distinct from those of other sellers." Even though this definition is right, it is based on marketer's perspective and conceptualize brand only as a representation (Leiser 2004). When enhanced so as to include that of consumer's, as well, as Keller (2003) suggests, a brand is something that resides in the minds of consumers, i.e. it's about how customers think and feel about what the product actually delivers them It is also "a schema or a semantic network which the consumer has acquired through a process of learning" (Strebinger et al. 1998). Consumers have abstract associations next to performance-related associations in memory, which together form a general meaning of the product in their minds. These abstract imagery-related associations reflect characteristics of the products not restricted to the product 
itself (Keller 2003). They reflect what consumer think about the brand considering the extrinsic properties and other intangible aspects such as experiences, purchase and usage situations, user profiles, brand/user congruence. Brand image can be formed by creating favorable, unique and strong associations through direct, e.g. experiences, or indirect ways, e.g. wordof-mouth, advertising.

Once consumers acquire a favorable a brand meaning in terms of performance and image through conscious or non-conscious learning processes, these learned associations serves as a schema and lead to priming during the buying and consumption process. Priming process based on favorable brand associations help consumers to easily perceive and interpret brand related information, such as risks and quality of the product, identity of the source (e.g. producer, dealer) and symbols attached to the product. Gürhan-Canlı and Rajeev (2004), for instance, found that certain types of corporate image associations (such as innovativeness and trustworthiness but not social responsibility) have a great impact on consumer evaluations of an individual product made by that company in purchase decision situations in which a high level of risk is perceived. In this case, corporate image serves as a schema.

\section{LEARNING BRAND IMAGE ASSOCIATIONS}

Solomon (2007, p.128) points to the controversy surrounding the issue whether consumers' learning is conscious or not. Behavioral learning theories are primarily based the assumption that learning occurs trough non-conscious conditioning. The theory of classical conditioning which was reported by Pavlov in his experiment with dogs assumes that when a previously neutral stimulus is paired with an unconditioned stimulus several times, the neutral stimulus becomes conditioned and is able to elicit a conditioned response even in the absence of the unconditioned stimulus (e.g. Kleinman et al. 2001, Solomon 2007). Cognitive learning theories criticize the automatic and non-conscious nature of conditioning and assume that even in conditioning subject exert cognitive effort, i.e. form conscious expectancies. Expectations which lead the consumer to behave in a certain way are activated by beliefs. Expectancy theory suggests that, a hypothetical expectancy (e.g., "If I buy brand X, I will experience $Y$ level of satisfaction") and it is this belief that produces behavioral outcomes and perceived efficacy of the treatment (e.g. Stewart-Williams 2004, Kardes and Cronley 2000). Expectancies can be acquired directly or trough indirect sources such as observations, word-of mouth. Direct experiences are more effective than others. 


\section{PLACEBO EFFECTS AND THE MECHANISMS FOR PLACEBO}

The etymology of the term 'placebo' comes from Latin and means to please (Macedo et al. 2003). Placebo is a very well known and researched concept in medical sciences. Despite controversiesabout its definition (e.g. Moerman (2001, Macedo et al. 2003, Tilburt et al.2008); most researchers (Kirsch 2005) define is as physically inert substances that are identical in appearance to an active drug, yet have little or no pharmacological activity, such as sugar pills. Placebos are supposed to promote positive psychological effects. Tilburt et al. (2008) define a "placebo treatment" as a treatment whose benefits (in the opinion of the clinician) derive from positive patient expectations and not from the physiological mechanism of the treatment itself. Placebo effect is often defined as the response of patients to inert treatments.

Moerman (2001) exemplifies a British study, in which 835 women who used analgesics for headache were randomly assigned to one of four groups. One group received aspirin labeled with a widely advertised brand name. The other groups received the same aspirin in a plain package, or placebo marked with the same widely advertised brand name, or unmarked placebo. The active treatment groups reported more pain relief than placebo groups and branded preparations provided more pain relief than did non-branded ones. Innumerable similar cases are documented in medical literature; most of them report positive effect of placebo, while some others do not. Pointing to this inconsistency in findings, Kirsch (2005) suggests that some conditions are not amenable to placebo treatment. Kleinman et al. (2001 p.12) state that psychosocial factors such as personality, cognition (including, expectancy), social learning, and conditioning are presumed to activate psycho-physiological events that involve not only the nervous, endocrine, and immune systems, but also the cardiovascular, gastrointestinal, and other systems.

The medical literature on placebo effects proposes that placebo effects and why and when placebos do work can be attributed to classical conditioning and expectancies (e.g. Kleinman et al. 2001, Price et al. 1999, Stewart-Williams 2004, Stewart-Williams and Podd 2004). Recent studies document support for both theories, i.e. report that learning can occur through both non-conscious responses to conditioning procedures and/or conscious responses based on expectancies. Several researchers (Berns 2005, Roche 2007, Kirsch 2005, Stewart-Williams and Podd 2004) point to another view that suggests that even though conditioning procedures appears to result non-conscious response, conditioning and other sources of information sometimes shape conscious expectancies and that these expectancies can trigger responses. Supporting this notion, Price et al. (1999) and Benedetti et al. (2003) observed that expectancies can mediate conditioned responses. Patients, when conditioned by physicians or external information sources, such as advertising, word-ofmouth, develop outcome and efficacy expectations that the prescribed 
medication is beneficial (improved mood, less anxiety, reduced pain, and improved health status) (Kleinman et al. 2001).

Benedetti et al.'s (2003) study findings contributed to this framework by suggesting that placebo responses are mediated by conditioning when unconscious physiological functions such as hormonal secretion are involved, whereas they are mediated by expectation when conscious physiological processes such as pain and motor performance come into play, even though a conditioning procedure is performed.

\section{DO MARKETING ACTIONS RESULT IN PLACEBO EFFECTS?}

After Shiv et al. (2005), in a series of experiments, revealed that marketing actions can also result in placebo effect, i.e. marketing actions, such as pricing, can alter the actual efficacy of products to which they are applied (p.383), the phenomenon attracted some attention (e.g. Irmak et al. 2005, Rao 2005, Borsook and Becerra 2005). Basing their primary assumption that consumers' beliefs and expectations, shaped by experiences in their daily lives, often influence their judgments of products and services can influence reality; Shiv et al. (2005) found that price can exert non-conscious influence on expectancies about product quality, which in turn have an impact on perceived product performance. In their experiments, they demonstrated that the more a person pays for a beverage advertised to increase mental acuity, the bigger the performance enhancing effect should be. When participants' attention was drawn to the price, the effect was weakened, suggesting that the placebo effect may occur beyond awareness. This result supports that consumers' nonconscious beliefs about the price-quality relationship influence their outcome and efficacy expectations and change the perceived efficacy of the product (Irmak et al. 2005, Rao 2005). In this study, expectations played an apparent mediator role. Irmak et al. (2005, p. 408) extended these results by demonstrating the importance of motivation. In their study, the placebo energy drink was capable of raising blood pressure, increasing physical reflexes, enhancing mental alertness, and raising the self-reported arousal level for the participants. Motivation as a person's desire to experience the product's purported benefits played an important role; they revealed these placebo effects were only observed for highly motivated participants.

According to Shiv et al.'s (2005b) model, global beliefs (about e.g. price-quality relationship) indirectly and external cues (e.g. verbal suggestions, advertising claims) directly activate product-specific beliefs about product's intrinsic and extrinsic aspects. Salient beliefs activate response expectancies which in turn together with other factors such as self-efficacy beliefs and related expectancies give rise to the subjective/behavioral outcomes.

These studies that examine placebo effect of marketing actions mostly base their theoretical framework on classical conditioning with acknowledging the 
mediator role of expectancies and motivation, as medical literature does. Indeed, without referring to placebo literature, several studies revealed that consumers' motivations, global and/or product-specific beliefs and response expectancies have impact on perceived product performance; for instance Bridges (1993) demonstrated that when consumers with a specific usage situation in mind judge their perception of a product or service attribute, their responses depend in a predictable manner upon their reference point, or expectations for the usage situation. Ewald and Moskowitz (2007) found that the brand, as an extrinsic aspect of the product, frames expectations for a product execution. Moreover, Punj and Hillyer (2004) suggest that the activated brand heuristic, decision rules used by consumers that favor to tap associations that are available, reduce cognitive effort and brand heuristic mediates global brand attitude and choice. Heuristics may be seen as a part of global or productspecific beliefs which activate response axpectancies.

Since brand equity serves to create favorable, unique and strong associations in consumers' minds and signal to the credibility of these brand associations, it can result in placebo effects. Positive brand equity provides goodwill value in the face of uncertainty and serves as a source for product-specific beliefs and expectancies.

\section{EXPERIMENT: PLACEBO EFFECT OF HIGH-BRAND- IMAGE SOFT DRINKS}

Although the placebo phenomenon is very recently introduced to the marketing literature, current studies did address to brand image as a possible source of placebo effect, but have not studied it so far. Shiv et al. (2005, p.391) suggest that cola can taste very differently when one knows it is 'the real thing' (a Coke) versus when the very same product is mislabeled as a generic brand. Following this suggestion, in order to document evidence of a placebo effect caused by brand image, we conducted an experiment with Coca Cola and a domestic Turkish brand, Cola Turka. Coca Cola occupies the first place in global brand value rankings for several years (see interbrand.com). Coca Cola brand is also full of cultural meanings and, thus, has been center of many studies. For instance, medical researchers McClure et al. (2004) demonstrated the placebo effect of brand equity on behaviors. They delivered Coke and Pepsi to human subjects in behavioral taste tests and also in passive experiments carried out during functional magnetic resonance imaging (fMRI). When brands are deliveredanonymously, they observed a consistent neural response in the ventromedial prefrontal cortex that correlated with subjects' behavioral preferences for these beverages. In the brand-cued experiment, they explored that brand knowledge had a dramatic influence on expressed behavioral preferences and on the measured brain responses and in case an image of a Coke can preceded Coke delivery, significantly greater brain activity was observed in the dorsolateral prefrontal cortex, hippocampus, and midbrain relative to Coke delivery preceded by a circle of light. 
The theoretical framework of our study is inspired by Shiv et at.'s (2005b) model mentioned before. In the experiment, participants are delivered Cola Turka in Coca Cola cans. The participants were unaware of the researchers' manipulation of the drink. They completed the questionnaire before and after they consumed the drink. Participants elaborated on their expectancies about the efficacy of the drink, in the first step, and then they are asked to rate the perceived efficacy of the drink on a 5-point Likert scale. Statements in the questionnaire are mainly inspired from Shiv et at.'s (2005a) and Irmak et al.'s (2005) studies.

An experiment has been conducted with 200 participants in 2008. Data are collected in cafes and major shopping and entertainment areas during daytime in İzmir via convenience sampling method. After a pilot test with 10 respondents, the questionnaire was revised so that inapplicable questions and ambiguous wording could be avoided. Thus, clear instructions were provided throughout the questionnaire. Majority of the respondents are female (54,6\%), undergraduate level educated (52\%), students (55,3\%). Additional demographic and socio-economic characteristics of the sample appear in Table 1. The profile demonstrates us that mostly younger and educated people are interviewed. The reason of this uneven distribution may be attributed to the convenience samplingmethod utilized in the study. Apparently, this profile provides a limitation for generalization of the findings of the study. Participants who consume cola drinks frequently make up $94,5 \%$ of the sample. Among those who prefer Coca Cola constitutes $91 \%$, while Pepsi and Cola Turka is preferred at $9 \%$ and $3 \%$ respectively.

To assess participants' expectations, participants are asked to answer questions; "Do you believe that Coca Cola will, in general, meet your needs?" "How likely is it that Coca Cola will, in general, meet your expectations?". Those who prefer Coca Cola has salient beliefs and positive response expectancies about Coca Cola, 92\% reported that they believe in its efficacy in term of meeting their expectations and $91 \%$ percent reported that they have positive expectancies about its performance.

After consuming the cola drink (Cola Turka was served in Coca Cola can) $78 \%$ stated that they found support their beliefs about the efficacy of the drinks and $79,4 \%$ of them reported that their expectancies are confirmed. Only $18 \%$ of respondents who consume cola regularly could not find any support their belief and $16 \%$ of them could not confirm their expectancies. One sample t-tests support this findings; at $95 \%$ confidence level, frequent cola consumers found support for their beliefs about the efficacy of the drinks $(t=8,7 \mathrm{df}=130 \mathrm{p}=0,000)$ and confirmed their expectations $(t=6,9 \mathrm{df}=130 \mathrm{p}=0,000)$ after consuming the manipulated drink. There is also a strong correlation between the salient product-specific beliefs and perceived product performance (Pearson $r=0,891$ $\mathrm{p}<.00$ ). Even these preliminary findings indicate a placebo effect of brand image. However, this placebo effect does not appear to be strong. Paired sample t-test results indicate a slight difference between response expectancies 
and confirmation of them $(\mathrm{t}=-3,5 \mathrm{df}=130 \mathrm{p}=0.001)$. Before the treatment, respondents agreed to the statement (mean $=1,74$ std.dev. $=0,71$ ) "How likely is it that Coca Cola will, in general, meet your expectations?", while after the treatments their level of agreement dropped to a slightly lower level of agreement (mean=2,16 std.dev.=1,1), but did fall on the "neither agree nor disagree" point. Considering this finding, we can assume that participants, in general, either felt that the drink is manipulated in the experiment or found little differences in its taste.

Table 1: Demographic and Socio-Economic Characteristics of the Sample

\begin{tabular}{|c|c|c|c|c|c|}
\hline Variables & $\mathrm{N}$ & $\begin{array}{l}\text { Valid } \\
\text { Percent }\end{array}$ & Variables & $\mathrm{N}$ & $\begin{array}{l}\text { Valid } \\
\text { Percent }\end{array}$ \\
\hline \multicolumn{3}{|l|}{ Sex } & \multicolumn{3}{|l|}{ Education } \\
\hline Female & 107 & 54,6 & Literate & 1 & 1 \\
\hline Male & 89 & 45,4 & Primary School & 20 & 14 \\
\hline Missing & 4 & -- & High School & 23 & 16 \\
\hline \multirow[t]{5}{*}{ Total } & 200 & 100 & Vocational school & 22 & 15 \\
\hline & & & Undergraduate & 76 & 52 \\
\hline & & & Graduate & 3 & 2 \\
\hline & & & Missing & 55 & - \\
\hline & & & Total & 200 & 100 \\
\hline \multicolumn{3}{|c|}{ Age $($ Mean $=24,86$ Std.Dev. $=6,9)$} & \multicolumn{3}{|l|}{ Income (YTL) } \\
\hline Less than 20 & 35 & 27 & $0-499$ & 6 & 4 \\
\hline $21-25$ & 50 & 38 & $500-999$ & 17 & 12 \\
\hline $26-30$ & 25 & 19 & $1.000-1.499$ & 23 & 16 \\
\hline $31-35$ & 10 & 8 & $1.500-1.999$ & 30 & 21 \\
\hline $36-40$ & 6 & 5 & $2.000-2.499$ & 38 & 26 \\
\hline $41-45$ & 3 & 2 & $2.500-2.999$ & 30 & 21 \\
\hline higher than 46 & 2 & 1 & $3.000-3.499$ & 1 & 1 \\
\hline Missing & 16 & -- & $3.500-3.999$ & 0 & 0 \\
\hline \multirow[t]{3}{*}{ Total } & 200 & 100 & higher than 4.000 & 0 & 0 \\
\hline & & & Missing & 55 & -- \\
\hline & & & Total & 200 & 100 \\
\hline
\end{tabular}

Employment Status

Private Sector Officer

Public Sector Officer

Private Sector Employee

Public Sector Employee

Self-employed Profession

Small-scale trader

Retired

Housewife

Student

Unemployed

Other

Missing

Total

$\begin{array}{rr}13 & 9 \\ 3 & 2 \\ 21 & 14 \\ 1 & 1 \\ 9 & 6 \\ 2 & 1 \\ 5 & 3 \\ 9 & 6 \\ 80 & 55 \\ 1 & 1 \\ 1 & 1 \\ 55 & -- \\ 200 & 100\end{array}$


On the other hand, when we consider the finding that frequent cola consumers mostly $(73,3 \%)$ agreed to the statement "My perception about Coca Cola has an impact on my preference" (one sample t-test results $t=6,8 \mathrm{df}=130 \mathrm{p}=0,000$ ), we can suggest that there is a conscious placebo effect of brand image. Learning process whether trough non-conscious classical conditioning or conscious cognitive processes has resulted in a brand choice at the awareness level of consumers. This finding is consistent with Irmak et al.'s (2005) findings; they observed that the motivation that drove the placebo effect was conscious. They attributed their preferences to their social interactions with their peers $(t=5,99$ $d f=130 p=0,000)$ and other social agents $(t=4,5 d f=130 p=0,000)$. Personality was not reported as a significant variable that effect cola preference $(\mathrm{t}=0,7$ $d f=130 p=0,447)$.

Among the extrinsic and intrinsic aspects of the product, only price and brand image (extrinsicaspects) as product preference criteria are related with respondents salient product specific beliefs (Pearson chi-square $=17,01 \mathrm{df}=9$ $p=0,047$ and chi-square $=16,25 \mathrm{df}=8 \mathrm{p}=0,039$ respectively), other aspects such as quality, and package design are not found related. Those who have stronger beliefs about the product found price less important and brand image more important compared to those who have weaker beliefs. Quality and price is also related response expectancies (Pearson chi-square $=17,49 \mathrm{df}=8 \mathrm{p}=0,025$ and chi-square $=29,52 \mathrm{df}=8 \mathrm{p}=0,000$ respectively). Furthermore, $95,4 \%$ of frequent cola consumers rated quality as the most important brand preference criterion ( mean $=1,43$ std. dev. $=1,44$ ), $87 \%$ of them rated brand image as the second important brand preference criterion (mean $=1,83 \mathrm{std} \cdot \mathrm{dev}=0,88$ ). $37 \%$ of the respondents declared that price is neither important nor unimportant, while $56,5 \%$ of them found it an unimportant variable (mean $=3,87$ std. dev. $=1,00$ ). Another finding also indicate that those who reported positive perceptions of Coca Cola found brand image as an important criterion in their product preference (Pearson chi-square $=24,35 \mathrm{df}=8 \mathrm{p}=0,002$ ). We can propose that cola consumers mostly develop product-specific beliefs and response expectancies based on quality, price and brand images of the product.

Gender and age is not found related with respondents' product-specific beliefs and response expectancies. Those frequent cola consumers who have low to medium level (lower than 1500 YTL) and who has primary and secondary education has slightly lower expectancies compared to others $(F=2,263$ $d f=6 / 124 p=0,042$ and $F=2,79 d f=5 / 125 p=0,020$ respectively). It appears that consumers with medium and higher level income and higher level of education has higher response expectancies.

\section{CONCLUSION AND FUTURE SUGGESTIONS}

As defined earlier in medical literature, "placebo treatment" is a treatment whose benefits derive from positive patient expectations and not from the physiological mechanism of the treatment itself. Placebo effect is the response of patients to treatments. The primaryassumption of applying the phenomenon to the 
consumption context is that consumers' beliefs and expectations, shaped by experiences in their daily lives, often influence their judgments of products and services can influence reality. Findings of previous studies in marketing literature supported this assumption and also found mixed results about whether the mechanism through which the placebo effect operated is conscious or not.

Relying on flourishing, yet very young, literature on placebo effect of marketing actions, in order to document evidence of a placebo effect caused by brand image, we conducted an experiment with Coca Cola and a domestic Turkish brand, Cola Turka. Although statistical analyses of experiment data indicate a placebo effect of brand image, this placebo effect, however, does not appear to be strong. Furthermore, Findings also indicated that there is a conscious placebo effect of brand image. Learning process whether trough non-conscious classical conditioning or conscious cognitive processes has resulted in a brand choice at the awareness level of consumers.

Since brand image involves abstractimagery-related associations, which are not restricted to the product itself and reflect what consumer think about the brand considering the extrinsic properties and other intangible aspects such as experiences, purchase and usage situations, user profiles, brand/user congruence and since placebo effect derive frompositive psychological expectations, we expected a very strong placebo effect of brand image. Instead, we have found a weak effect. This incongruity can be attributed to different reasons; first, participants, in general, either may felt that the drink is manipulated in the experiment or found a little difference in its taste. Second, the experiment is conducted trough only one experiment group and all participants are delivered the same manipulated drink. Designing the experiment with two groups, i.e. in addition to the one treatment group, one notreatment (control) group, could also be helpful in discovering if participants recognize manipulation or not. Thus, we can suggest repeating the experiment with a better design so as to get more insight into the phenomenon.

Findings also indicated a weak placebo effect which operates at the awareness level. Although Shiv et al. (2005) observed non-conscious placebo effect of pricing, our finding is consistent with Irmak et al.'s (2005) findings; they observed that the motivation that drove the placebo effect was conscious. In order to acquire deeper insights into the mechanism through which placebo effect of brand image operated, once again, a research design with one treatment group and one no-treatment (control) group could be utilized.

Priming process based on learned favorable brand associations help consumers to easily perceive and interpret brand related information, such as risks and quality of the product, identity of the source and symbols attached to the product. In this study, we have found that cola consumers mostly prime on quality and brand images of the product and consequently develop productspecific beliefs and response expectancies. 
Obviously, this experimental study has its limitations; first, because of the budget problems, participants are sampled trough convenience sampling procedure which caused an unevenly distributed sample. Thus, generalizability of the findings is limited. A random sampling method may be more beneficial in future researches. Second, the research design encompasses one treatment group to whom the placebo drink is delivered, thus, as mentioned before, in addition to the one treatment group, one no-treatment(control)group, can be designed. Third, questionnaire statements are inspired from Shiv et at.'s (2005a) and Irmak et al.'s (2005) studies. In order to reach to more insightful understandings, future studies can be designed on enriched research instruments.

\section{REFERENCES}

Adaval, Rashmi (2003), "How Good Gets Better and Bad Gets Worse: Understanding the Impact of Affect on Evaluations of Known Brands", Journal of Consumer Research, 30, 3, 352-367.

American Marketing Association (2008), Dictionary, http://www.marketingpower. com/_layouts/Dictionary.aspx?dLetter=B. (01.11.2008)

Benedetti Fabrizio, Antonella Pollo,Leonardo Lopiano,Michele Lanotte,Sergio Vighetti,and Innocenzo Rainero (2003), "Conscious Expectation and Unconscious Conditioning in Analgesic, Motor, and Hormonal Placebo/Nocebo Responses", The Journal of Neuroscience, (May 15), 23, 10, 4315-4323.

Berns Gregory S. (2005), "Price, Placebo, and the Brain”, Journal of Marketing Research, (November), 42, 399-400.

Borsook, David and Lino Becerra (2005), "Placebo: From Pain and Analgesia to Preferences and Products", Journal of Marketing Research , (November), 42, 394-398.

Bridges, Eileen (1993), "Service Attributes: Expectation and Judgments", Psychology \& Marketing, (May/June), 10, 3, 185-197.

Bridges, Eileen (1993), "Service Attributes: Expectation and Judgments", Psychology \& Marketing, (May/June), 10, 3, 185-197.

Esch Franz-Rudolf, Bernd H. Schmitt, Joern Redler and Tobias Langner (2007), "The Brand Anchoring Effect: A Judgment Bias Resulting from Brand Awareness and Temporary Accessibility", Advances in Consumer Research North American Conference Proceedings, 34, 498-499.

Ewald, Jeff and Howard Moskowitz (2007), "The Push-Pull of Marketing and Advertising and the Algebra of the Consumer's Mind", Journal of Sensory Studies, (Apr), 22, 2, 126-175. 
Fabrizio Benedetti, Antonella Pollo, Leonardo Lopiano, Michele Lanotte, Sergio Vighetti, and Innocenzo Rainero (2003), "Conscious Expectation and Unconscious Conditioning in Analgesic, Motor, and Hormonal Placebo/Nocebo Responses", The Journal of Neuroscience, 23, 10, 4315-4323.

Gürhan-Canli, Zeynep; Batra, Rajeev (2004), "When Corporate Image Affects Product Evaluations: The Moderating Role of Perceived Risk". Joumal of Marketing Research, May2004, 41, 2, 197-205.

Irmak, Caglar; Lauren G. Block, and Gavan J. Fitzsimons, (2005), "The Placebo Effect in Marketing: Sometimes You Just Have to Want It to Work", Journal of Marketing Research, (November), 42, 406-409.

Kardes, Frank R. and Marı L.Cronley (2000), "The Role of Approach/Avoidance Asymmetries in Motivated Belief Formation and Change", The Why Of Consumption: Contemporary Perspectives On Consumer Motives, Goals, And Desires, S.Ratneshwar, David Glen Mick, and Cynthia Huffman (eds), London: Routledge, 81-97.

Keller, Kevin Lane (2003), Strategic Brand Management: Building, Measuring and Managing Brand Equity, USA: Pearson International Edition.

Kirsch Irving (2005), "Placebo Psychotherapy: Synonym or Oxymoron?" Journal of Clinical Psychology, 61, 7, 791-803.

Kleinman, Arthur, Harry A Guess and Joan S Wilentz (2001), "An Overview", The Science of The Placebo: Toward An Interdisciplinary Research Agenda, Harry A Guess, Arthur Kleinman, John W Kusek and Linda W Engel (eds.), London: BMJ Publishing, 1-32

Leiser, Michael (2004), “Understanding Brand's Value: Advancing Brand Equity Tracking To Brand Equity Management", Marketing in the 21st Century, Bradford, Emerald Group Publishing, 217-221.

Macedo Ana, Magi Farre and Josep-E. Banos (2003), "Placebo Effect and Placebos: What Are We Talking About? Some Conceptual and Historical Considerations", European Journal of Clinical Pharmacology, 59: 337-342.

McClure Samuel M., Jian Li, Damon Tomlin, Kim S. Cypert, Latané M Montague, and P.Read Montague (2004), "Neural Correlates of Behavioral Preference for Culturally Familiar Drinks", Neuron, (14 October), 44, 2, 379-387.

Moerman, Daniel E (2001), "Explanatory Mechanisms For Placebo Effects: Cultural Influences and The Meaning Response" , The Science of the Placebo: Toward An Interdisciplinary Research Agenda, Harry A Guess, Arthur Kleinman, John W Kusek and Linda W Engel (eds.), London: BMJ Publishing, 77-107. 
Pain and placebo analgesia: two sides of the same coin.Preview By: Roche, Patricia A.. Physical Therapy Reviews, 2007, Vol. 12 Issue 3, p189-198,

Price DD, Milling LS, Kirsch I, Duff A, Montgomery GH, Nicholls SS. (1999), An Analysis of Factors That Contribute to the Magnitude of Placebo Analgesia in an Experimental Paradigm", Pain , 83, 147- 56.

Punj, Girish N. and Clayton L Hillyer (2004), "A Cognitive Model of CustomerBased Brand Equity for Frequently Purchased Products: Conceptual Framework and Empirical Results", Journal of Consumer Psychology, 14, 1/2, 124-131.

Rao, Akshay R(2005), "The Quality of Price as a Quality Cue", Journal of Marketing Research , (November), 42, 401-405.

Roche, Patricia A..(2007), "Pain and Placebo Analgesia: Two Sides of the Same Coin”, Physical Therapy Reviews, 12, 3, 189-198.

Shiv, Baba, Ziv Carmon, and Dan Ariely (2005a), "Placebo Effects of Marketing Actions: Consumers May Get What They Pay For", Journal of Marketing Research, (November), 42, 383-393.

Shiv, Baba; Ziv Carmon and Dan Ariely (2005b), "Ruminating About Placebo Effects of Marketing Actions", Journal of Marketing Research, (November), 42, 410-414.

Simonson, Itamar and Aimee Drolet (2004), "Anchoring Effects on Consumers' Willingness-to- Pay and Willingness-to-Accept", Journal of Consumer Research, (Dec), 31, 3, 681-690,

Solomon, Michael R. (2007), Consumer Behavior: Buying, Having and Being, 8th ed., USA: Pearson International Edition.

Stewart-Williams Steve (2004), "The Placebo Puzzle: Putting Together the Pieces", Health Psychology, 23, 198-206.

Stewart-Williams, Steve (2004), The Placebo Puzzle: Putting Together the Pieces, Health Psychology, 23, 2, 198-206.

Stewart-Williams, Steve and John Podd (2004), "The Placebo Effect: Dissolving the Expectancy Versus Conditioning Debate", Psychological Bulletin, (Mar), $130,2,324-340$.

Strebinger,Andreas, Günter Schweiger and Thomas Otter (1998), "Brand Equity and Consumer Information Processing: A Proposed Model", AMA's Marketing Exchange Colloquium,Vienna.

Tilburt Jon C, Ezekiel J Emanuel, Ted J Kaptchuk, Farr A Curlin, and Franklin G Miller (2008), "Prescribing "Placebo Treatments": Results of National Survey of US Internists and Rheumatologists", British Medical Journal, 337:a1938, 1-5. 